\title{
Transcatheter Closure of a Large Muscular Ventricular Septal Defect (VSD) in a Child Weighing Five Kilogram with Severe Pulmonary Arterial Hypertension
}

\author{
Begum NNF \\ DOl:https://doi.org/10.3329/jafmc.v16i2.55307
}

\begin{abstract}
Ventricular septal defect (VSD) is the commonest congenial heart lesion which may close spontaneously in significant number of cases. Muscular VSD has better chance of spontaneous closure. Some of the large muscular VSDs may cause severe complications like pulmonary hypertension and intractable heart failure. Closing VSD in young infant is challenging specially with devices as delivery systems are too large comparing to size of femoral vessels. Some centre prefers hybrid procedure of per ventricular device closure as surgical closure is high risk in young infants with complications. Here a case of large muscular VSD with severe pulmonary hypertension is reported in a ten month old girl which was closed successfully with a Konar- MFTM device and patient was discharged after 24 hours.
\end{abstract}

Key-words: Transcatheter Closure, Ventricular Septal Defect (VSD), Pulmonary Arterial Hypertension.

\section{Introduction}

Ventricular septal defect (VSD) is the most commonly encountered congenital cardiac malformation with an incidence of 3.85/1000 live births ${ }^{1-3}$. In premature infants incidence is 4.5 to 7 per thousand live birth ${ }^{4}$. Lower prevalence in adult with congenital heart disease is mainly due to spontaneous closure in early childhood ${ }^{5}$. Small VSD is usually asymptomatic and often close spontaneously. The reported rate of spontaneous closure varies between $56-75 \%^{1}$. Color Doppler echocardiography can diagnose these defects with high degree of specificity and sensitivity, which has resulted in an increased prevalence of VSD at birth ${ }^{6-9}$. Surgical closure of haemodynamically significant VSD's are long been established. Transcatheter closure of muscular VSD was first attempted on a compassionate basis using Rashkind device ${ }^{9}$. Amplatzer VSD occluder (muscular) was undergoing clinical trial since $1988^{10}$. In small children with less body weight, intraoperative device closure of muscular VSD is practiced by surgeons. Hybrid procedures are performed in operation theatre with $\mathrm{C}$-arm of angiography machine, specially for children with less body weight ${ }^{11,12}$. In this case, VSD device closure was performed for large muscular VSD using a 6 French right coronaryJudkins guide catheter as delivery system through right femoral artery, thus high risk surgery was avoided.

\section{Case Report}

F, a 10 months old girl reported to paediatric cardiology outpatient department of a cardiac hospital 2 months ago with severe respiratory distress and failure to thrive. Her body weight was $5 \mathrm{~kg}$ during initial reporting. Mother gave history of feeding difficulty and recurrent chest infection also. On examination short systolic murmur was heard over upper left sternal border with loud second heart sound. Chest X-ray showed mild cardiomegaly. ECG showed biventricular hypertrophy. Echocardiography showed large upper muscular VSD of $9 \mathrm{~mm}$ with bidirectional shunt. Calculated peak pulmonary artery systolic pressure was $70 \mathrm{~mm} \mathrm{Hg}$. Patient was advised with oral Furosemide, Enalapril and sildenafil. Patient came for follow up after one month and VSD size reduced to $7 \mathrm{~mm}$, Pulmonary artery pressure was still high but shunt direction was changed from left to right. Patients weight was still $5 \mathrm{~kg}$ and suffered from pneumonia once in brief follow up time. Patient was planned for device closure with Konar -MFTM (Lifetech scientific) from retrograde approach and was taken into cath lab on 25th June 2021 after all preoperative check up. She was draped and connected to monitoring system. Later she was sedated with injection Ketamine, Injection Midazolum and Injection Phenobarbitone, lowest dose of each in cocktail combination. Right femoral artery was cannulated with $5 \mathrm{~F}$ introducer sheath first and patient was fully heparinized. Left ventricular angiography showed a large upper muscular ventricular septal defect (VSD), size measured was 7.5 $\mathrm{mm}$. An $8 \times 6 \mathrm{~mm}$ size Konar- MFTM device was connected to delivery cable and was loaded to loader. VSD was crossed initially with 4 French JR4 Catheter and Terumo guide wire and then exchanged with $6 \mathrm{Fr}$ sheath and $6 \mathrm{Fr}$ guide catheter. Loader was connected to guide catheter and one disc was released first to right ventricle. Whole system was pulled back to interventricular septum (IVS) and larger end of the device was then released to left ventricle. Transthoracic Echo and fluoroscopy guide was taken to monitor the procedure and to check encroachment of aortic valve cusp. No aortic regurgitation (AR) and residual shunt was noticed in Echocardiography, Left Ventriculography and Aortogram. Haemostasis was normal and there were no postoperative complications or arrhythmia. Pressure bandage was removed after 24 hours and loosened after 4 hours of procedure. Additional injection heparin was given at 50 unit/kg 4 hours after device implantation. Aspirin $5 \mathrm{mg} / \mathrm{kg}$ was advised for three months. Procedure time was 20 minutes and fluoroscopy time was 4.5 minutes. Femoral pulse returned back after 30 minutes of the procedure. Echocardiography was repeated before discharge and device position was found excellent without any AR. Patient was discharged after 24 hours observation with follow up plan at 1,3,6,12,18,24 months and yearly thereafter for 03 years.

Brig Gen Nurun Nahar Fatema Begum, SBP, FCPS, FRCP, FACC, FSCAI, Professor and Head, Department of Paediatrics, AFMC, Dhaka \& Advisor Specialist in Paediatric Cardiology, CMH, Dhaka (E-mail: colfatema@hotmail.com) 


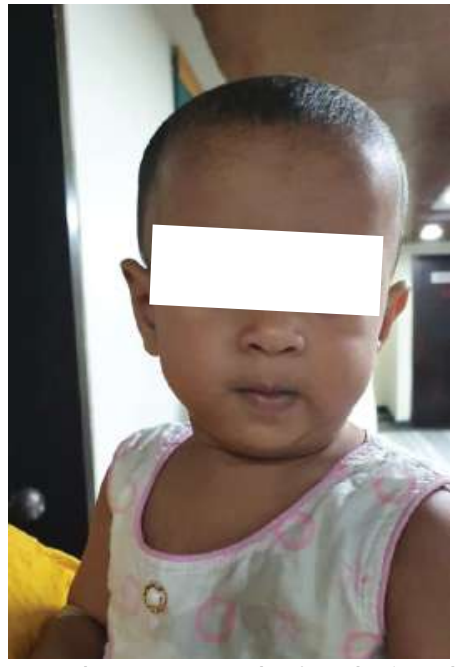

Figure-1: Baby F, one week after device closure.

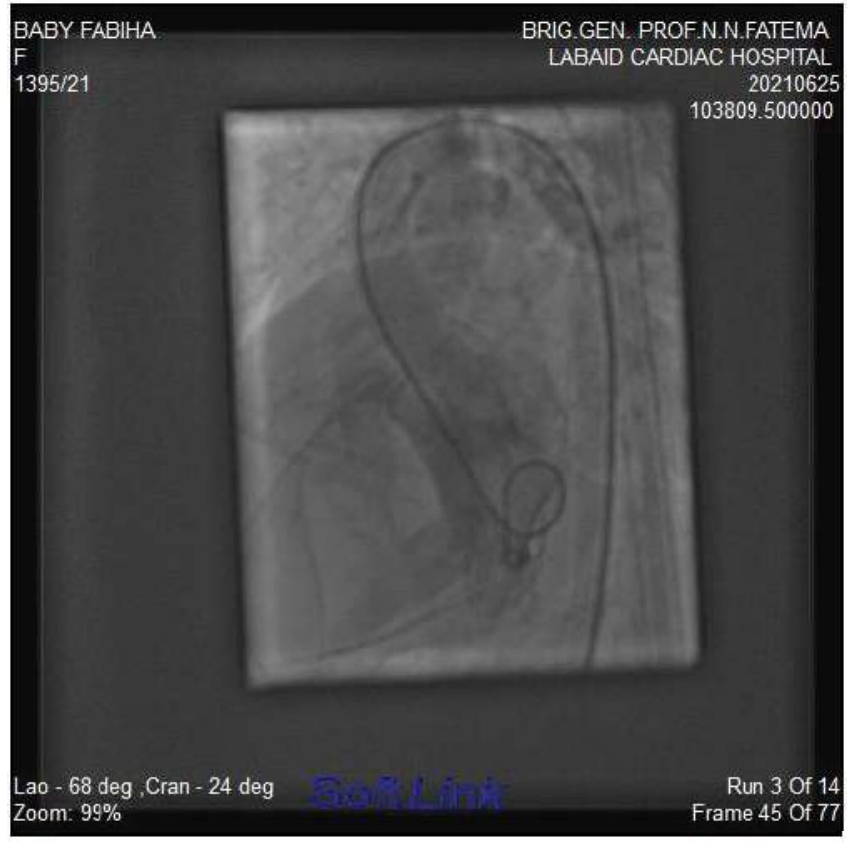

Figure-2: LV angiogram showed large upper muscular VSD.

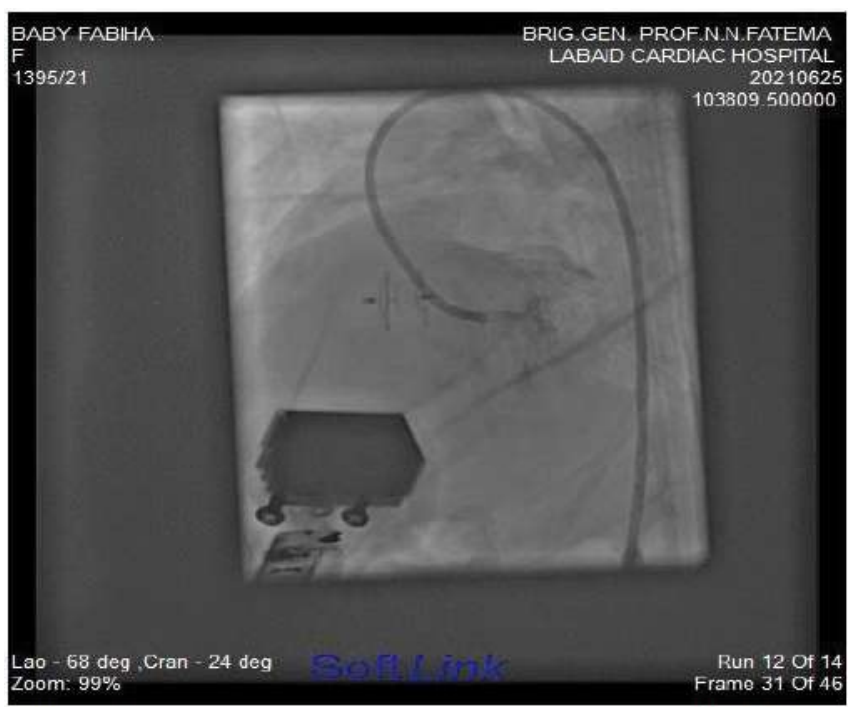

Figure-3: Konar MF TM 8x6 mm device in position and no residual shunt or AR.

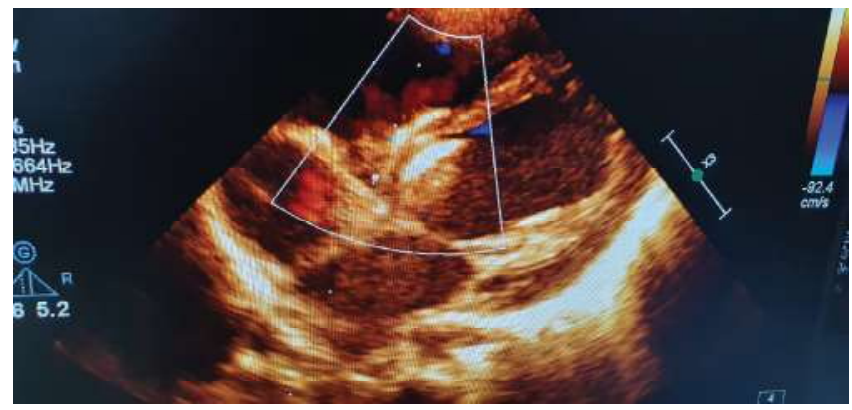

Figure-4: Echocardiography on next day showed VSD device in nice position.

\section{Dscussion}

Closing VSD's with the Amplatzer muscular VSD device (MVSD) from AGA medical corporation was in practice since 90's. Multiple studies proved efficacy and excellent outcome of this method of closure $^{13-18}$. Surgical closure of muscular VSD still poses some challenges because of course trabeculation on right ventricular side and difficult to localize from standard surgical approaches. Overall mortality and rate of residual VSD's after surgery remain higher than that of perimembraneous VSD' $s^{15}$. Device closure of muscular VSD in neonate or infant's with body weight less than $05 \mathrm{~kg}$ is challenging. So, alternative options are in evolution for these border line cases, when VSD closure is mandatory for uncontrolled heart failure, recurrent pneumonia and failure to thrive ${ }^{12}$. One modality for this group of children is intraoperative perventricular device closure on the beating heart which was first reported in $1998^{19}$. Later various studies proved the benefit of combined surgical and interventional technique (hybrid) on borderline babies. Closure of muscular VSD specially in the apical septum needs cannulation of internal jugular vein, femoral arteries on both sides, general anesthesia and transoesophageal echocardiography guidance ${ }^{13}$. These are technically not feasible in young infants with weight equal or less than $5 \mathrm{~kg}$. Retrograde approach of closing perimembranous and muscular VSD's using Judkins guide catheter as delivery system is an established technique in our center, where multifunctional Konar-MFTM and $\mathrm{ADO}^{11}$ from Abbot vascular device were used as closure device ${ }^{14}$. Konar-MF was found feasible, safe and effective in many studies ${ }^{20-22}$. Advantage of Konar MFTM (Lifetech scientific, China) is because of its softer design, double ended disc, feasibility for both antegrade and retrograde use and small size delivery system $^{20}$. In our center, we use coronary guide catheter $(5 F, 6 F$ Judkinsright guide catheter) which further reduces the cost. This baby was not gaining body weight, her pulmonary artery pressure was very high and surgery was a very high risk one. So we decided for device closure in retrograde approach using a $6 \mathrm{~F}$ guide catheter and patient was discharged after 24 hour with an excellent outcome.

\section{Conclusion}

Detection rate of muscular VSD is high due to availability of doppler echocardiography. Because of high prevalence of muscular VSD's in newborn and young infant, some children with large VSD need early closure. Surgery is high risk and passage of large delivery 
system is also hazardous through small femoral vessels. Hybrid procedure needs thoracotomy. So retrograde approach of closure using soft Konar-MFTM is a good alternative for this special group of infants with less body weight.

\section{References}

1. Roguin N, Du ZD, Barak M et al. High prevalence of muscular ventricular septal defect in neonates. J Am Coll Cardiol. 1995; 26(6):1545-8.

2. Martin GR, Perry LW, Ferencz C. Increased prevalence of ventricular septal defect: Epidemic or improved diagnosis. Pediatrics. 1989; 83(2):200-3.

3. Miyake T. A review of isolated muscular ventricular septal defect. World J Pediatr. 2020; 16(2):120-8.

4. Hoffman JIE and Rudolph AM. The natural history of ventricular septal defects in infancy. The American Journal of Cardiology 1965; 16(5):634-53.

5. Moe DG and Guntheroth WG. Spontaneous closure of uncomplicated ventricular septal defect. The American Journal of Cardiology. 1987; 60(8):674-8.

6. Layde PM, Erickson JD, Dooley K et al. Is there an epidemic of ventricular septal defects in The U.S.A.? The Lancet. 1980; 315(8165):407-8.

7. Fixler DE, Pastor $P$, Chamberlin $M$ et al. Trends in congenital heart disease in Dallas County births (1971-1984). Circulation. 1990; 81(1):137-42.

8. Snider AR, Bengur AR. Two dimensional and Doppler echocardiography in the evaluation of congenital heart disease. In: Macus ML, Schelbert HR, Scorton DJ, Wolf GL, bramwold E, editors. Cardiac Imaging. A companion to Brawnwelds Heart disease. Philladelphia Saunders. 1991:479-510.

9. Sommer RJ, Golinko RJ, Ritter SB et al. Intracardiac Shunting in Children With Ventricular Septal Defect : Evaluation With Doppler Color Flow Mapping. J AM Col Cardiol. 1990; 16:1687-95.

10. Arora R, Trehan V, Thakur AK et al. Transcatheter closure of muscular Ventricular septaldefect. J Intervcardiol. 2004; 17:109-15.

11. Okubo M, Benson LN, Nykanen D et al. Outcomes of intraoperative device closure of muscular ventricular septal defects. The Annals of Thoracic Surgery. 2001; 72(2):416-23.

12. Haponiuk I, Chojnicki M, Jaworski R et al. Hybrid approach for closure of muscular ventricular septal defects. Medical Science Monitor. 2013; 19(1):618-24.

13. Fatema N, Rahman M and Haque M. Device Closure of Ventricular Septal Defect with Amplatzer Muscular Occluder: A Case Report. Journal of Bangladesh College of Physicians and Surgeons. 2007; 25(3):161-3.

14. Fatema NN. Ventricularseptal defect from retrograde transarterial approach: Immediate and long-term. Int J Contemp Pediatr. 2020; 7:1830-6.

15. Holzer R, Balzer D, Cao QL et al. Amplatzer Muscular Ventricular Septal Defect Investigators. J Am Coll Cardiol. 2004; 43(7):1257-63.

16. Chessa M, Carminati M, Cao QL et al. Transcatheter closure of congenital and acquired muscular ventricular septal defects using the Amplatzer device. J Invasive Cardiol. 2002; 14(6):322-7.

17. Holzer R, Balzer D, Amin Z et al. Transcatheter closure of postinfarction ventricular septal defects using the new Amplatzer muscular VSD occluder: Results of a U.S. Registry. Catheter Cardiovasc Interv. 2004; 61(2):196-201.

18. Maddali MM, Al-Maskari SN, Kandachar PS et al. Transesophageal echocardiography-assisted transcatheter device closure of apical muscular ventricular septal defect. Saudi J Anaesth. 2019; 13(2):148-50.

19. Amin Z, Berry JM, Foker JE et al. Intraoperative closure of muscular ventricular septal defect in a canine model and application of the technique in a baby. J Thorac Cardiovasc Surg. 1998; 115(6):1374-6.

20. Tanidir IC, Baspinar O, Saygi M et al. Use of LifetechTMKonar-MF, a device for both perimembranous and muscular ventricular septal defects: A multicentre study. International Journal of Cardiology. 2020; 310:43-50.

21. Bjorkman KR, Aldoss O, Maldonado JR et al. Transcatheterutilisation of lifetech multifunction ${ }^{\mathrm{TM}}$ occluder device for closure of perimembranous and muscular ventricular septal defects: First use in North America. Cardiol Young. 2021; 26:1-3

22. Barbosa JD, Alonso J, Ferrín L et al. Endovascular VSD Closure with Lifetech KONAR-Multifunctional Occluder - Novel Device. Structural Heart Disease. 2019; 5(6):237-47. 